\title{
Loss of bcbrn1 and bcpks13 in Botrytis cinerea Not Only Blocks Melanization But Also Increases Vegetative Growth and Virulence
}

\author{
Chenghua Zhang, Yifan He, Pinkuan Zhu, Lu Chen, Yiwen Wang, Bing Ni, and Ling Xu
}

School of Life Science, East China Normal University, Shanghai 200241, PR China

Submitted 18 April 2015. Accepted 26 May 2015.

\begin{abstract}
Botrytis cinerea is a necrotrophic pathogen that causes gray mold disease in a broad range of plants. Dihydroxynaphthalene (DHN) melanin is a major component of the extracellular matrix of $B$. cinerea, but knowledge of the exact role of melanin biosynthesis in this pathogen is unclear. In this study, we characterize two genes in $B$. cinerea, bcpks13 and bcbrn1, encoding polyketide synthase and tetrahydroxynaphthalene (THN) reductases, respectively, and both have predicted roles in DHN melanin biosynthesis. The $\Delta b c p k s 13$ and $\Delta b c b r n 1$ mutants show white and orange pigmentation, respectively, and the mutants are also deficient in conidiation in vitro but show enhanced growth rates and virulence on hosts. Moreover, the mutants display elevated acidification of the complete medium (CM), probably due to oxalic acid secretion and secretion of cell wall-degrading enzymes, and preferably utilize plant cell-wall components as carbon sources for mycelium growth in vitro. In contrast, overexpression of $b c b r n 1$ (OE::bcbrn1 strain) results in attenuated hydrolytic enzyme secretion, acidification ability, and virulence. Taken together, these results indicate that bcpks13 and bcbrn1 participate in diverse cellular and developmental processes, such as melanization and conidiation in $B$. cinerea in vitro, but they negatively regulate the virulence of this pathogen.
\end{abstract}

Botrytis cinerea is considered one of the most important fungal plant pathogens, causing gray mold disease in more than 200 plant species globally (Dean et al. 2012). The disease cycle of $B$. cinerea usually begins with the attachment of its spores on host surfaces, followed by germination and development of appressorium-like structures during the infection process (Gourgues et al. 2004; Jarvis 1977; Tenberge 2004). However, $B$. cinerea does not produce the typical appressorium of rice blast pathogen Magnaporthe oryzae, which accumulates high turgor pressure to drive mechanical penetration through the host epidermis (Leroch et al. 2013). B. cinerea is commonly considered as a representative necrotrophic pathogen, which kills plant tissue prior to invasion and proliferation, and its secreted virulence factors (e.g., lytic enzymes, reactive oxygen species [ROS], oxalic acid, and toxins) are critical for

Corresponding authors: P. Zhu; E-mail: pkzhu@bio.ecnu.edu.cn; and L. Xu; E-mail: 1xu@bio.ecnu.edu.cn. Telephone: +862154341012; Fax: +862154341006 .

*The $e$-Xtra logo stands for "electronic extra" and indicates that four supplementary figures and two supplementary tables are published online.

(C) 2015 The American Phytopathological Society successful invasion (Choquer et al. 2007; Heller and Tudzynski 2011; Kars and van Kan 2007). Additionally, B. cinerea can also conquer hosts via the manipulation of plant defense mechanisms (El Oirdi et al. 2011; Weiberg et al. 2013). Due to these versatile weapons and broad range of crops that it attacks in pre- and postharvest, control of $B$. cinerea is difficult and costly worldwide (Choquer et al. 2007; Dean et al. 2012).

Melanin pigments are polymers formed by oxidative polymerization of phenolic or indolic compounds, which are produced by a remarkable variety of organisms, including bacteria, fungi, plants, and animals (Bell and Wheeler 1986; Butler and Day 1998). A great variety of functions have been ascribed to melanin (Hill 1992). In fungal species, melanin is usually involved in protection against various stresses, including UV radiation, heavy metals, desiccation, hydrolytic enzymes, oxidatives, heat or cold, and fungicides (Akamatsu et al. 2010; Butler and Day 1998; Liu and Nizet 2009). Two melanin biosynthetic pathways have been identified, the dihydroxyphenylalanine pathway (Singh et al. 2013) and the dihydroxynaphthalene (DHN) pathway (Bell and Wheeler 1986; Singh et al. 2013).

The DHN pathway is conserved among filamentous ascomycetes and has been investigated in many plant pathogens, including Alternaria spp. (Kawamura et al. 1999; Kheder et al. 2012), Cochliobolus heterotrophus (Eliahu et al. 2007), Colletotrichum spp. (Ludwig et al. 2014), genera Gaeumannomyces (Frederick et al. 1999) and Magnaporthe (Thompson et al. 2000), Bipolaris oryzae (Kihara et al. 2004), Phyllosticta musarum (Kubo and Furusawa 1991), and Verticillium dahliae (Wheeler et al. 1978). In the DHN pathway, it is generally believed that acetyl-CoA is the substrate of polyketide synthases (PKS), which produce the precursor 1,3,6,8-tetrahydroxynaphthalene $(1,3,6,8-\mathrm{THN})$. $1,3,6,8-\mathrm{THN}$ is reduced by THN reductase to scytalone, which is converted to DHN following dehydration and reduction steps. DHN, finally, is polymerized to DHN melanin (Butler and Day 1998). Fungi can produce DHN melanin during different times of development, such as appressorial differentiation, late stationary mycelial growth, and spore formation (Tsuji et al. 2000). In $M$. oryzae, deletion of the melanin synthesis genes $3 H N R$, encoding 1,3,8-trihydroxynaphthalene (1,3,8-THN) reductase, and $4 H N R$, encoding 1,3,6,8-THN reductase, resulted in less pigment in appressoria, which failed to generate high turgor pressure and lost the ability to mechanically penetrate (Thompson et al. 2000). Similarly, in Colletotrichum lagenarium, melanin synthesis-deficient mutants showed loss of penetration and virulence (Kubo et al. 1991; Perpetua et al. 1996; Wang et al. 2001). However, in fungi that do not form melanized appressoria, the role of melanin in infection is poorly understood. Alternaria alternata mutants defective in $A L M 1$, encoding PKS, and $B R M 2-1$, encoding 
THN reductase, were unable to produce melanin but showed normal virulence (Kheder et al. 2012), and mutants of Bipolaris oryzae lacking PKS1 (encoding PKS) caused necrotic lesions on rice leaves comparable to the wild-type strain (Moriwaki et al. 2004).

In $B$. cinerea, the DHN-type melanin has been chemically detected in the extracellular matrix of germlings, conidiophores, conidia, and sclerotia (Doss et al. 2003; Zeun and Buchenauer 1985). In the genome of B. cinerea (strain B05.10), four genes, including bcpks13 and bcpks12 (encoding PKS), bcbrnl (encoding THN reductase), and bcscdl (encoding scytalone dehydratase), were predicted to be involved in melanin biosynthesis (Amselem et al. 2011; Schumacher et al. 2014). Expression of these genes was found to be regulated by mitogen-activated protein kinase pathways (Liu et al. 2011), the light-responsive transcription factor BcLTF1 (Schumacher et al. 2014), the heterotrimeric velvet complex BcVeA/BcVelB (Yang et al. 2013a), and two putative protein tyrosine phosphatases BcPtpA and BcPtpB (Yang et al. 2013b). However, the exact role of these melanin biosynthesis enzymes in the pathogenesis of $B$. cinerea remains to be elucidated.

In this study, we investigated the functions of the melanin synthesis-related genes bcbrnl and bcpks 13 of B. cinerea, using targeted gene deletion. Lack of bcbrnl and bcpks13 abolished melanin accumulation and conidiation in vitro. However, the mutants exhibited a higher vegetative growth rate and a greater secretion of known virulence factors than the wild-type strain. Based on the data obtained, we raise the hypothesis that these two melanin biosynthesis genes, $b c b r n 1$ and $b c p k s 13$, negatively regulate virulence factors in this necrotrophic fungal pathogen.

\section{RESULTS}

Melanin synthesis-related genes are induced to various extents during different developmental stages of $B$. cinerea.

There are four genes predicted to encode enzymes for DHN melanin biosynthesis in B. cinerea, including bcpks 12 (BC1G_06876), bcpks13 (BC1G_14497), bcbrn1 (BC1G_04230), and bcscd1 (BC1G_14488) (Amselem et al. 2011; Schumacher et al. 2014). The transcriptional patterns of these genes were detected by quantitative reverse transcription-polymerase chain reaction (qRT-PCR) during different fungal developmental stages (Fig. 1). The expression level of each gene at $8 \mathrm{~h}$ (early germination stage) was used as the baseline value. The expression levels of bcpks 12 and bcpks 13 at $10 \mathrm{~h}$ were elevated four- and sixfold, respectively, followed by a slight drop at 12 and $24 \mathrm{~h}$. After that, the transcripts of bcpks 12 and bcpks 13 increased and the highest transcript level of bcpks 13 occurred after 7 days (sporulation stage), while the expression peak for bcpks 12 was found in sclerotia. Transcript levels of the other two genes, bcbrn 1 and $b c s c d 1$, did not increase before $12 \mathrm{~h}$, but after $12 \mathrm{~h}$, their expression continuously increased until the sporulation stage (7 days), at which time both genes reached peak levels of expression.

\section{Sequence analysis of BcPKS13 and BcBRN1.}

PKS and hydroxynaphthalene reductase (BRN) are the key enzymes for DHN melanin biosynthesis in fungi. The homologs encoding these two proteins in $B$. cinerea, namely bcpks 13 and bcbrn1, were analyzed. The bcpks13 gene is 6,542 bp in length with one intron, encoding a 2,138-amino acid protein named BcPKS13. The PKS mainly contains six domains: two ketoacyl synthase (KS) domains, one acyl transferase (AT) domain, two acyl carrier protein (ACP) domain, and a thioesterase (TE) domain (Supplementary Fig. S1). The amino-acid sequence homology of these domains between BcPKS13 and the homologs of Bipolaris oryzae, Aspergillus fumigatus, M. oryzae, and Colletotrichum lagenarium were approximately $81.7 \%$ (N_KS), 76.5\% (KS_C), 68.6\% (AT), 67.8\% (ACP1), $67.4 \%$ (ACP2), and $60.7 \%$ (TE). The bcbrnl gene is 979 bp in length with two introns, encoding a 289-amino acid protein named BcBRN1 that is highly similar to homologs in Colletotrichum lagenarium (78\%), Bipolaris oryzae (71\%), Cochliobolus heterostrophus (71\%), Alternaria alternata (69\%), and M. oryzae (74\%) (Supplementary Fig. S2).

\section{Generation of bcbrn1 and bcpks13 null mutants and bcbrn1 overexpressing strains.}

To investigate the function of melanin synthesis-related genes in B. cinerea, we generated null mutants of bcbrnl and bcpks13, which were replaced with a hygromycin resistance-gene cassette (Supplementary Fig. S3A). Two bcbrnl deletion mutants were identified by PCR analysis with the primers 9 and 16, named $\Delta b c b r n 1-3$ and $\Delta b c b r n 1-8$ (Supplementary Table 1). A Southern blot hybridization assay confirmed that homologous recombination events occurred at the bcbrnl locus in the mutants. For the bcpks13 gene, two deletion mutants, named $\Delta$ bcpks13-13 and $\Delta b c p k s 13-20$, were also obtained and confirmed by PCR analysis with the primers 19 and 28. Additionally, we obtained three bcbrnl overexpressing (OE::bcbrnl) strains, OE::bcbrn1-1, OE::bcbrn1-14, and OE::bcbrn1-18, in which the exogenously introduced $b c b r n 1$ was ectopically expressed under control of the promoter of constitutive bcactA. qRT-PCR showed that the transcription levels of bcbrnl in all three OE::bcbrnl strains were over fivefold higher than in the wild-type strain. Because all OE::bcbrnl strains showed identical phenotypes, two of them (OE::bcbrn1-1 and OE::bcbrn1-14) were used for further study.

\section{$\Delta$ bcbrn1 and $\Delta b c p k s 13$ mutants are deficient in melanin biosynthesis.}

As shown in Figure 2A, after 12 days of liquid culture with or without tricyclazole at $22^{\circ} \mathrm{C}$ under alternating light and dark conditions, the wild-type strain accumulated black pigment in yeast-sugar-salt (YSS) medium but produced orange pigment in YSS medium plus tricyclazole, an inhibitor of fungal DHN melanin biosynthesis. By contrast, the $\Delta b c b r n 1$ mutants accumulated orange pigment and the $\Delta b c p k s 13$ mutants did not accumulate obvious pigment with or without tricyclazole supplementation (Fig. 2A). In addition, the OE::bcbrnl strains had a similar phenotype to the wild-type strain and similar pigment phenotypes were observed when each strain was inoculated on solid CM, except for more melanization in OE::bcbrn1 strains (Fig. 3A). Additionally, supplementation with 1,8-DHN $(2.5 \mathrm{mM})$ restored hyphal melanization of $\Delta b c b r n 1$ and $\Delta b c p k s 13$ mutants (Fig. 2A). To further confirm the melanin deficiency phenotype of the mutants, melanin deposition was examined via the copper sulfide-silver staining method (Butler et al. 2005). Under light microscopy, copper sulfide-silver labeling revealed dark staining along hyphal cell walls and septa was extensively observed in the wild type and OE::bcbrnl strains (Fig. 2B). However, the dark staining was not detected in $\Delta b c b r n l$ or $\Delta b c p k s 13$ strains (Fig. 2B). These results confirm that $\Delta b c b r n 1$ and $\Delta b c p k s 13$ mutants are deficient in melanin biosynthesis.

\section{Involvement of bcbrn1 and bcpks13 genes in hyphal growth and conidiation.}

Compared with the wild type, radial growth of strain $\Delta b c b r n 1$ and $\Delta b c p k s 13$ colonies was approximately 28 and $7.5 \%$ faster than that of their corresponding parents on CM, 17 and $8.4 \%$ faster on potato dextrose agar medium, and 16 and $11 \%$ faster on YSS medium after 3 days (Fig. 3B). In addition, after 14 days, the wild type and OE::bcbrn1 strains formed gray 
to dark colonies covered with large numbers of conidia, whereas the $\Delta b c b r n 1$ and $\Delta b c p k s 13$ strains formed orange and white colonies, respectively, but no conidia on YSS media (Fig. $3 \mathrm{C})$. When incubated on $1 \%$ water agar covered with cellophane for $20 \mathrm{~h}$, both the $\Delta b c b r n 1$ and $\Delta b c p k s 13$ mutants had many more hyphal tip branches than the wild type and OE: bcbrnl strains and this branching pattern observed in $\Delta b c b r n 1$ was more obvious than that in $\Delta b c p k s 13$ (Fig. 4A). Additionally, to simulate the situation of penetration events on host cells, onion epidermal strips were inoculated with mycelial plugs. After $24 \mathrm{~h}$ postinoculation (hpi), the $\Delta b c b r n 1$ and $\Delta b c p k s 13$ strains formed more invasive hyphae than the wild-type strain, which significantly increased aerial hyphae formation with conidiophores at $36 \mathrm{hpi}$. As for the OE::bcbrnl strains, invasive

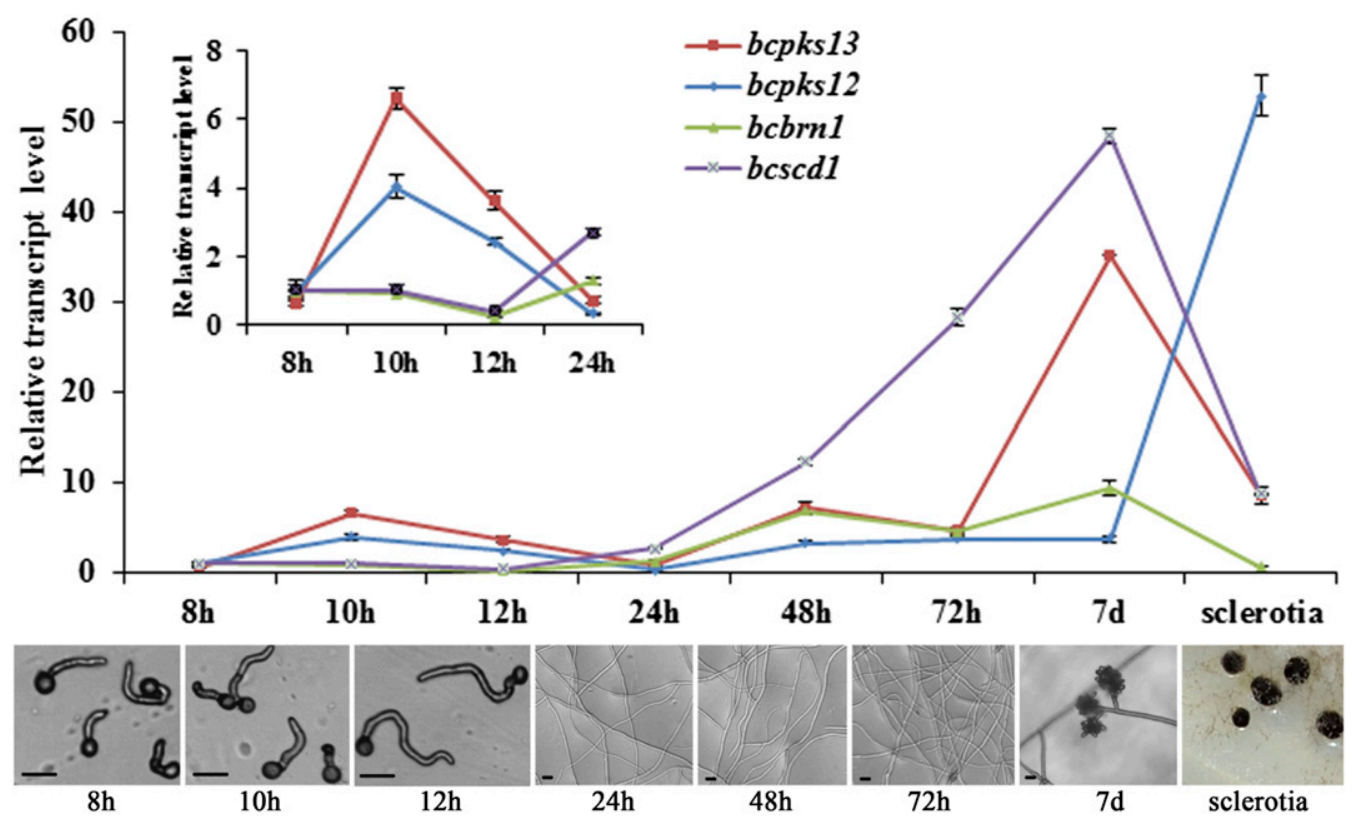

Fig. 1. Expression of the melanin synthesis genes during fungal development in strain B05.10 of Botrytis cinerea. Kinetic of B. cinerea development on cellophane using conidia as starting material. The RNA samples of eight stages: germinated conidia ( $8 \mathrm{~h})$, appressoria formation stages (10h to $12 \mathrm{~h})$, mycelia development stages ( $24 \mathrm{~h}$ to $72 \mathrm{~h}$ ), conidiation stage (7d) and sclerotia were collected from the cultures on yeast-sugar-salt media at $22^{\circ} \mathrm{C}$ under alternating light and dark conditions and were used for relative quantitative reverse transcription-polymerase chain reaction analysis (three biological repeats). The $\beta$-tubulin-encoding gene was used as an internal reference. The error bars indicate standard deviation of three experiments. The scale bars represent $10 \mu \mathrm{m}$.
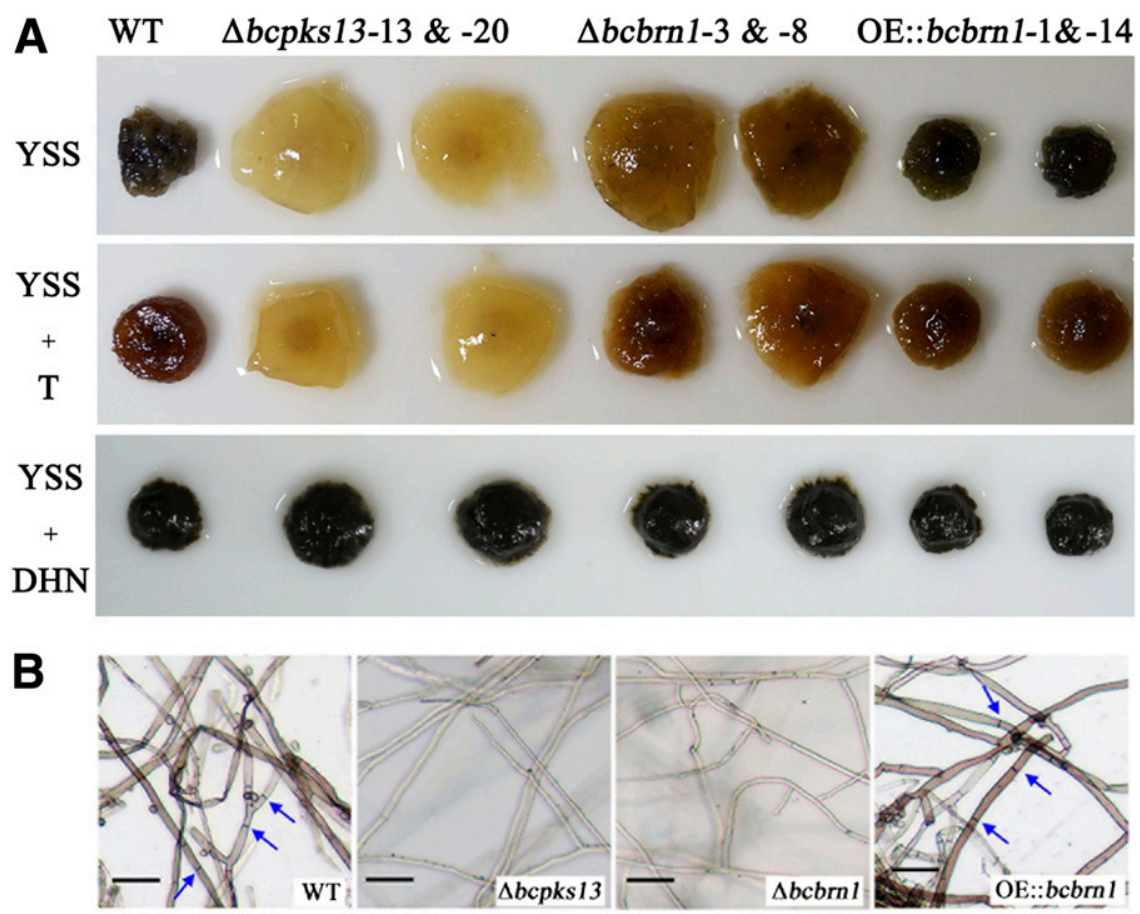

Fig. 2. Analyses of melanin production in $\Delta b c b r n 1$ and $\Delta b c p k s 13$ strains of Botrytis cinerea. A, Melanin biosynthesis of $\Delta b c b r n 1, \Delta b c p k s 13$, OE::bcbrn1, and wild-type strains. The strains were cultured in liquid yeast-sugar-salt media with or without $10 \mu \mathrm{g}$ tricyclazole (T) per milliliter for 12 days and $2.5 \mathrm{mM}$ 1,8-dihydroxynaphthalene (M) for 7 days. The cultures were placed at $22^{\circ} \mathrm{C}$ under alternating light and dark conditions. B, Copper sulfide-silver staining assay to detect fungal melanin under light microscopy. The blue arrows indicate the location of melanized hyphal septa, and the bars represent $25 \mu \mathrm{m}$. 
mycelia were rarely observed but aerial hyphae and conidiophores were more obvious than the $\Delta b c b r n 1$ and $\Delta b c p k s 13$ strains (Fig. 4B and C).

\section{$\Delta$ bcbrn1 and $\Delta b c p k s 13$ mutants} are more virulent than the wild-type strain.

The virulence of $\Delta b c b r n l$ and $\Delta b c p k s 13$ mutants was assessed by an artificial inoculation assay on several postharvest fruits and detached leaves. As shown in Figure 5, the lesion diameters induced by $\Delta b c b r n l$ were, on average, $17.4 \mathrm{~mm}$ on pepper and $25.9 \mathrm{~mm}$ on apple slices, significantly larger than those induced by the wild-type B05.10 strain (10.5 and $20.0 \mathrm{~mm})$ and the OE::bcbrnl strains (9.0 and $15.6 \mathrm{~mm}$ ). Similarly, the $\Delta b c p k s 13$ mutants also caused larger lesions than the wild type and OE::bcbrn1 strains (Fig. 5A, B, and C). Similar results were obtained on detached leaves of tobacco (Fig. 6). In addition, because ROS play a major role in the interactions between host plants and $B$. cinerea, we also checked ROS accumulation during infection on tobacco leaves, using staining with DAB (3, 3'-diaminobenzidine). The $\Delta b c b r n 1$ and $\Delta b c p k s 13$ mutants accumulated ROS more rapidly and abundantly than the wild type at the infection site at $48 \mathrm{~h}$ (Fig. 6).

\section{$\Delta b c b r n 1$ and $\Delta b c p k s 13$ mutants show increased growth on host cell-wall constituents.}

To explore the possible reasons for the enhanced virulence of $\Delta b c b r n 1$ and $\Delta b c p k s 13$ mutants, we compared their growth patterns with the wild type and OE::bcbrnl strains on media containing plant cell-wall constituents. On the basal YSS medium with glucose as carbon source, the colony diameter of $\Delta b c b r n 1$ trains were approximately $30 \%$ higher than those of wild type. However, the colony diameters of $\Delta b c b r n l$ were almost $80,70,60$, and $80 \%$ greater than those of the wild type when they were cultured on media supplemented with polygalacturonic acid (PGA), apple pectin, citrus pectin, and carboxymethyl cellulose (CMC) as carbon source, respectively. Similar growth trends were also observed for the $\Delta b c p k s 13$ mutants on those media. In contrast, the OE::bcbrn1 strains showed similar colony diameters as the wild type on all media except the one containing $\mathrm{CMC}$, on which the OE::bcbrn1 strains reached approximately half of the wild type's colony diameter (Fig. 7). These results indicate that deletion of the melanin synthesis-related genes bcbrnl or bcpks 13 allow the fungus to more effectively utilize.

\section{$\Delta b c b r n 1$ and $\Delta b c p k s 13$ mutants show higher secretion of virulence factors.}

$B$. cinerea relies on a range of plant cell wall-degrading enzymes to break down the plant tissue to release carbohydrates, which are major carbon sources for the pathogen. Therefore, we compared the secretory activities of several hydrolytic enzymes between the mutants and wild type. As evaluated with transparent-ring assays, both $\Delta b c b r n l$ and $\Delta b c p k s 13$ mutants expressed enhanced secretion for polygalacturonase and cellulase, whereas the OE::bcbrnl strains exhibited lower secretory ability of those hydrolytic enzymes than exhibited by the wild type (Fig. 8A, B, D, and E). When inoculated on the media for the protease secretion assay, both $\Delta b c b r n 1$ and $\Delta b c p k s 13$ mutants also had faster growth rates than wild type and OE::bcbrn1 strains (Fig. 8C and F). Furthermore, the $\Delta b c b r n 1$ and $\Delta b c p k s 13$ mutants also exhibited stronger acidification of the CM, probably due to oxalic acid secretion, than did the wild type and OE::bcbrn1 strains (Fig. $8 \mathrm{G})$. In addition, we analyzed transcript levels of the known virulence-related polygalacturonase-encoding gene bcpgl, the endo- $\beta-1,4$-xylanase-encoding gene $b c x y n 11 A$, and the oxaloacetate acetylhydrolase-encoding gene bcoahA in wild type,
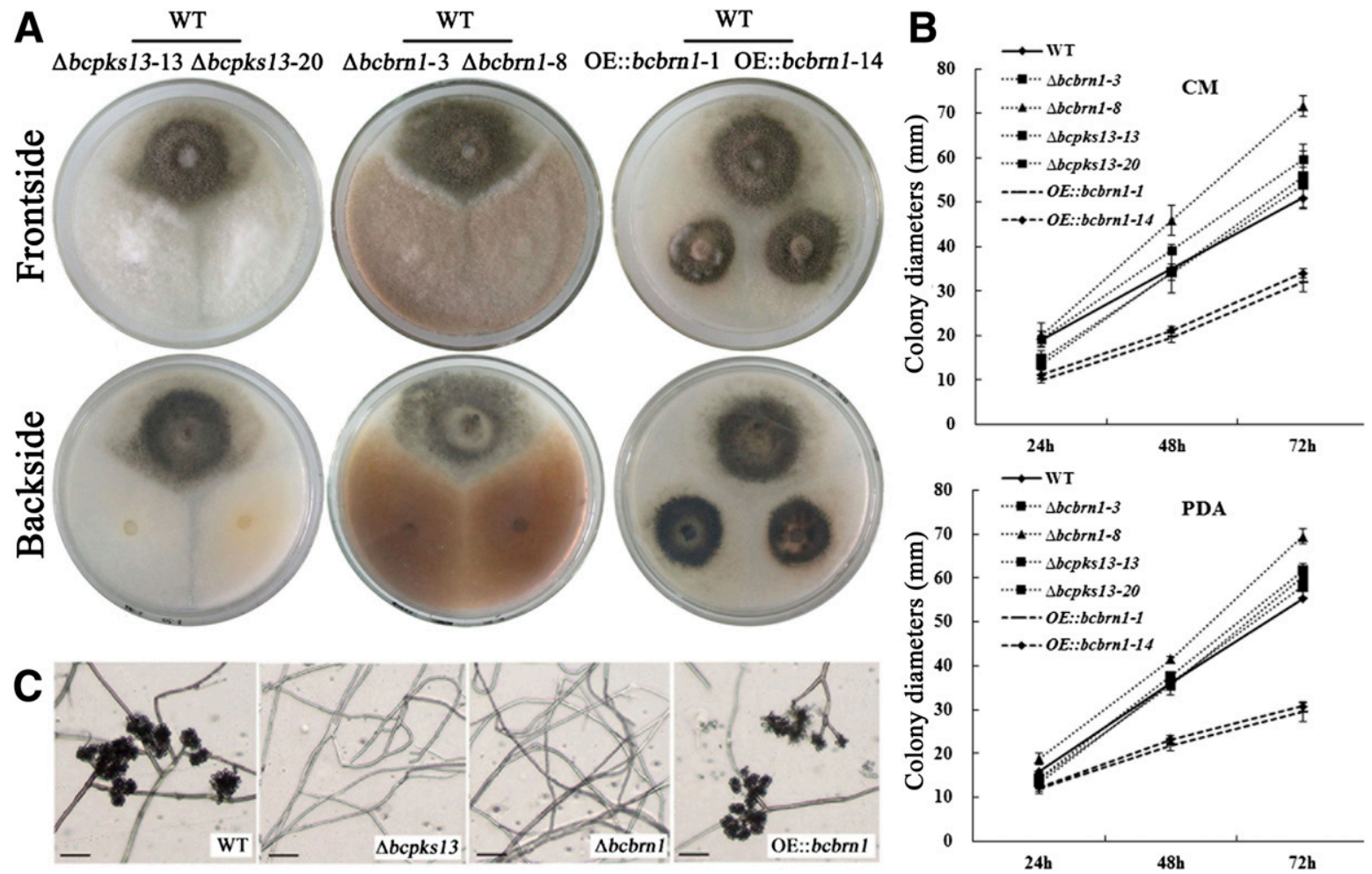

Fig. 3. Deletion of $b c b r n 1$ and $b c p k s 13$ affects vegetative growth and conidiation in Botrytis cinerea. A, Phenotypic variation. The cultures of each strain were grown on complete medium $(\mathrm{CM})$ for 5 days. B, Colony diameter among different cultures. PDA = potato dextrose agar. $\mathbf{C}$, Conidial production of the strains cultured on yeast-sugar-salt media for 14 days. The scale bars represent $50 \mu \mathrm{m}$. 
$\Delta b c p k s 13$, and $\Delta b c b r n 1$ inoculated on tobacco leaves after $48 \mathrm{~h}$. The transcript levels of bcpgl, bcoachA, and bcxynl1A in $\Delta b c p k s 13$ and $\Delta b c b r n 1$ were significantly up-regulated compared with the wild type (Supplementary Fig. S4). These results imply that $\Delta b c b r n l$ and $\Delta b c p k s 13$ mutants secrete virulence factors more actively than the wild-type strain.

\section{DISCUSSION}

DHN melanin has been detected via nuclear magnetic resonance in the extracellular matrix of $B$. cinerea (Doss et al. 2003). In $B$. cinerea, there are four genes predicted to encode the analogs of PKS (bcpks12 and bcpks13), THN reductase (bcbrnl), and dehydratase (bcscdl), which are the key enzymes for conventional fungal DHN melanin biosynthesis. Although the melanin synthesis-related enzymes from different fungal species are highly conserved, their functions in the regulation of development may vary significantly. The gene expression study in this work showed that the peak transcript levels of bcpks13, bcbrn1, and bcscdl occurred at the sporulation stage (approximately 7 days postinoculation), while the expression of $b c p k s 12$ was found to be in accordance with the data of Schumacher et al. (2014), who reported its peak transcript level occurred specifically in sclerotia. These findings may imply that melanin biosynthesis in $B$. cinerea could be involved in conidiation and sclerotia formation.
To address the role of melanin biosynthesis in the growth and disease cycle of $B$. cinerea, we created gene-deletion mutants of bcpks 13 and $b c b r n 1$ and characterized their phenotypes. The albino phenotype of $\Delta b c p k s 13$ mutants indicates that PKS plays a pivotal role of initiating the melanin biosynthesis pathway in $B$. cinerea, which was also observed in several other fungi, such as Alternaria alternata (Kheder et al. 2012) and Aspergillus nidulans (Tsai et al. 2001). Additionally, because tricyclazole specifically inhibits the fungal DHN melanin biosynthesis pathway at the THN reductase reaction steps, resulting in accumulated branching pathway products such as flaviolin (Tsai et al. 2001), the orange color of the $\Delta b c b r n 1$ mutants could be due to accumulation of the products in the branch pathways. Moreover, spore production was not observed when the $\Delta b c b r n 1$ and $\Delta b c p k s 13$ mutants were cultured on various media. Thus, it can be concluded that the melanin biosynthesis genes bcpks 13 and bcbrnl influence the conidial development of $B$. cinerea.

The $\Delta b c b r n 1$ and $\Delta b c p k s 13$ mutants showed an increased hyphal-branching pattern when inoculated on cellophane, compared with the wild type. The mechanism of this phenomenon remains to be characterized. One possible explanation could be that melanin is commonly reported to be located at fungal cell walls (Bell and Wheeler 1986; Eisenman and Casadevall 2012) and hyphal branching could be influenced by cell-wall assembly (Harris 2008). It is necessary to further
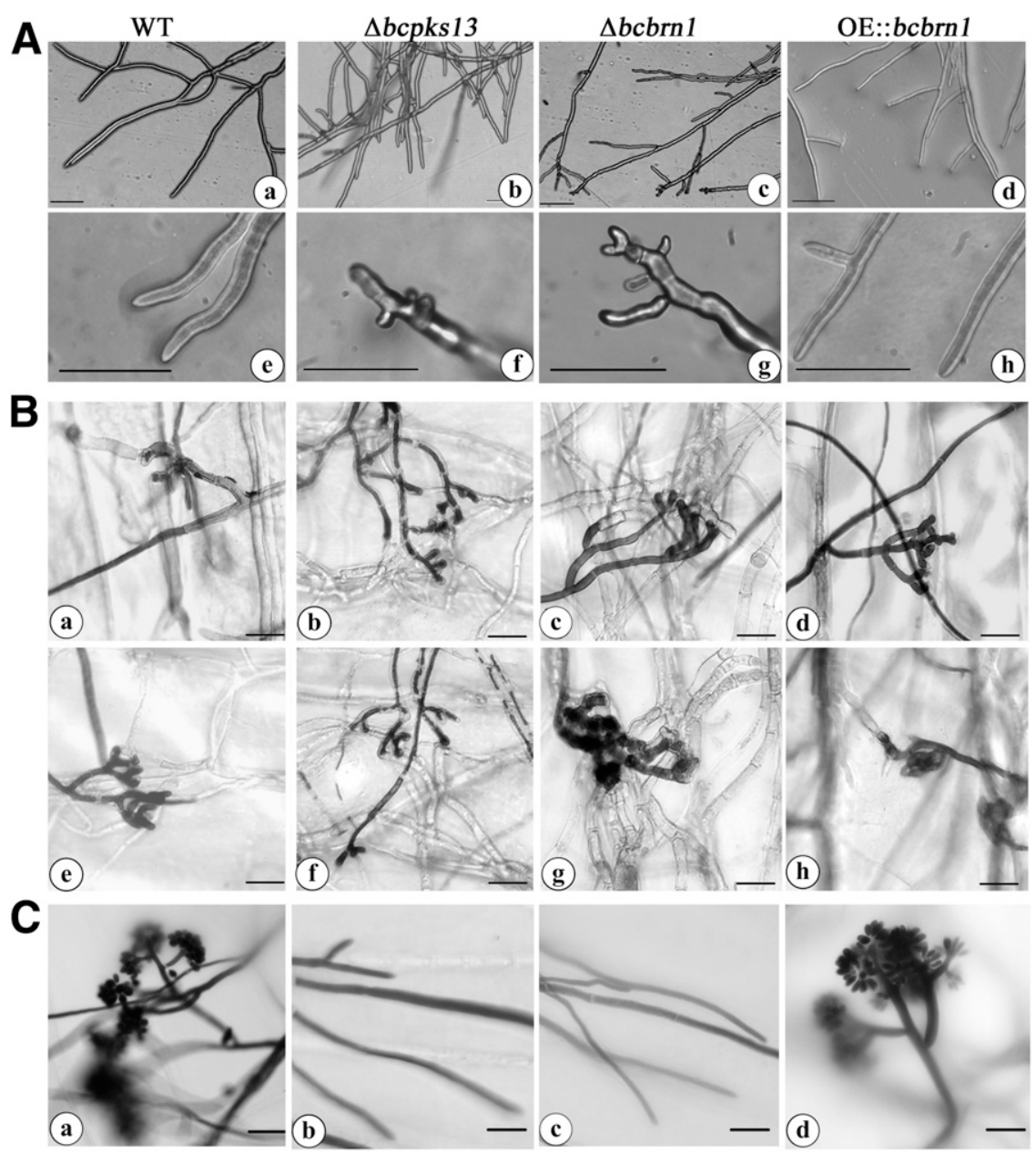

Fig. 4. Hyphal branching and infection mycelia formation in $\Delta b c b r n 1, \Delta b c p k s 13$ mutants and the overexpression strain (OE::bcbrn1) on both cellophane and onion epidermal layers. A, Deletion of bcbrnl and $b c p k s 13$ enhanced hyphal branching on potatp dextrpse agar media covered with cellophane. Pictures were taken at $20 \mathrm{~h}$ postinoculation (hpi). Scale bars, $50 \mu \mathrm{m}$. B, Deletion of $b c b r n 1$ and $b c p k s 13$ increased the formation of infection mycelia on onion epidermal layers. Onion epidermal strips were inoculated with nonsporulating mycelia. The vegetative hyphae on the surface could be stained with trypan blue, whereas infectious hyphae remained colorless. Scale bars, $25 \mu \mathrm{m}$. a, b, c, and d show infection status at 24 hpi and e, f, g, and h show infection status at 36 hpi. C, Conidia production of $\Delta b c b r n 1$ and $\Delta b c p k s 13$ mutants, OE::bcbrn1 and wild-type strains on onion epidermal layers at 24 hpi. The bars represent $25 \mu$ m. 

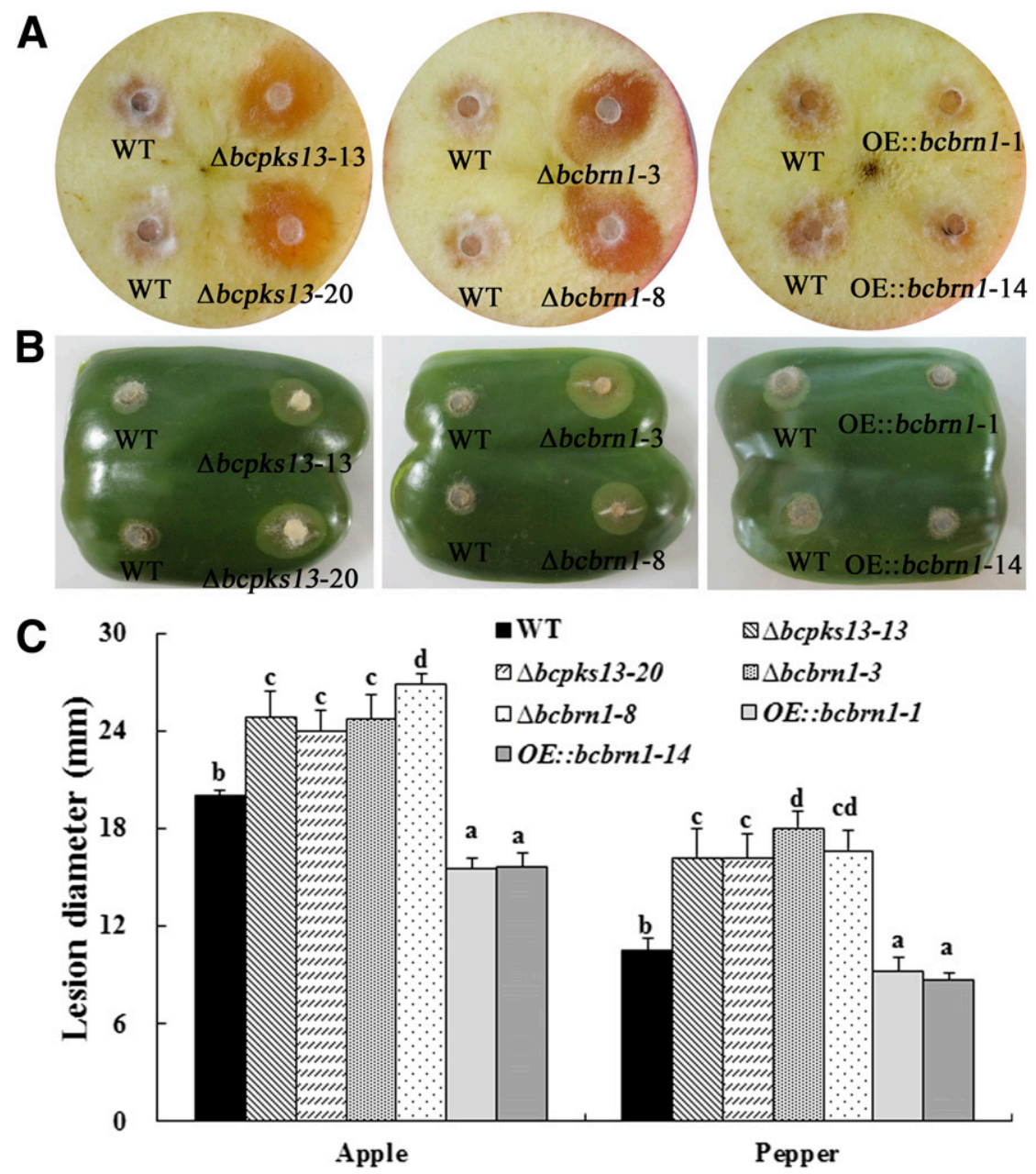

\section{$\mathbb{Q} \Delta b c p k s 13-13$ \\ 国 $\Delta b c b r n 1-3$ \\ OE::bcbrn1-1}

OE::bcbrn1-14

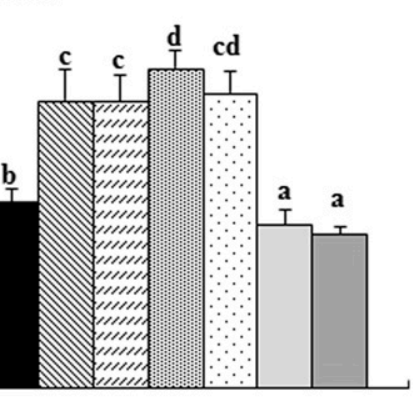

Pepper

Fig. 5. Analyses of the virulence of $\Delta b c b r n 1$ and $\Delta b c p k s 13$ strains of Botrytis cinerea on $\mathbf{A}$, apple slices ( 2 days postinoculation [dpi]) and $\mathbf{B}$, wound-inoculated pepper fruits (3 dpi) compared with wild type and OE::bcbrn1 strains. C, Lesion diameters caused by each strain on the two tested hosts.
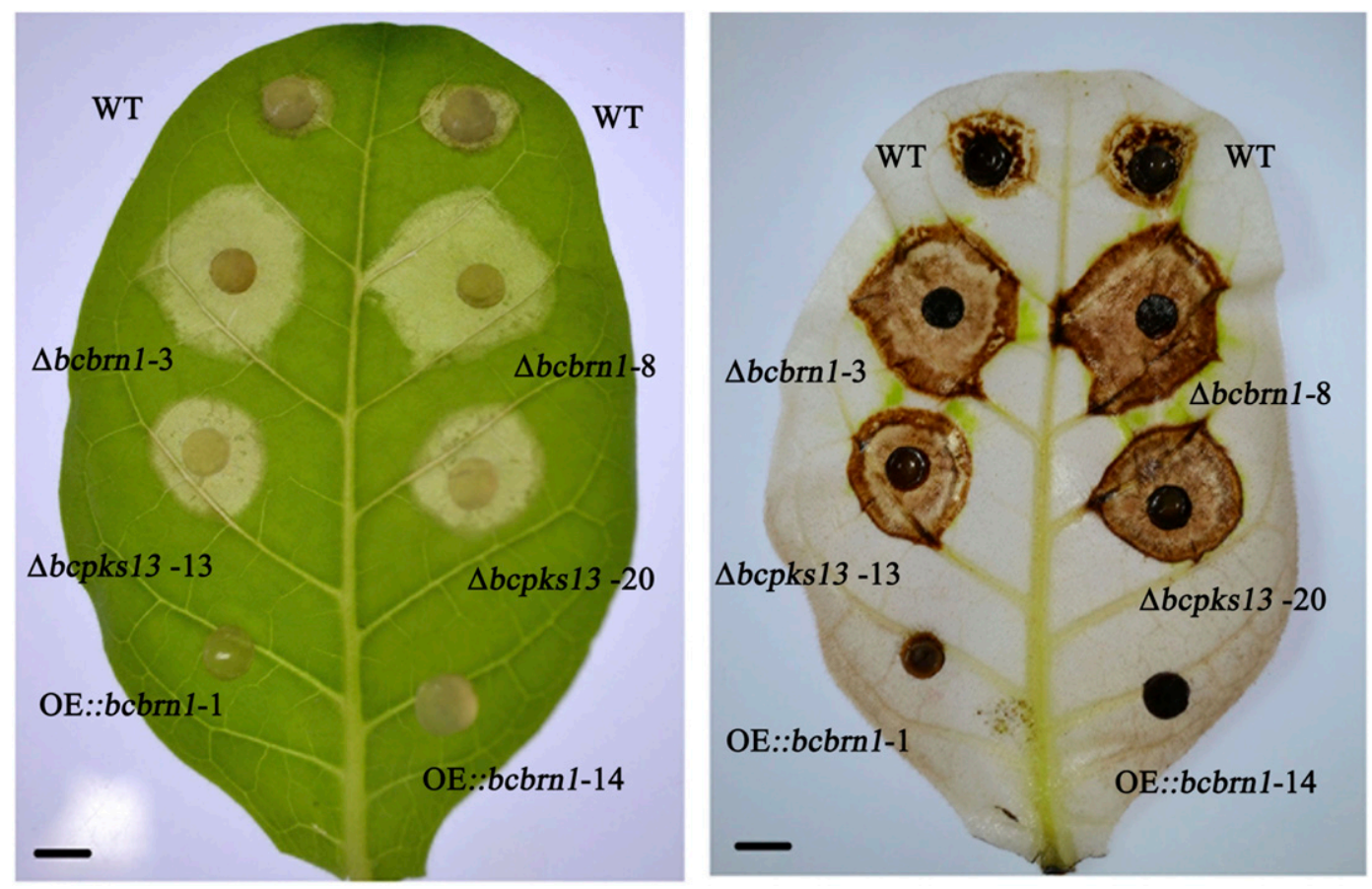

Fig. 6. Analyses of the virulence and reactive oxygen species (ROS) production of $\Delta b c b r n 1$ and $\Delta b c p k s 13$ strains of Botrytis cinerea on tobacco leaves. Detached tobacco leaves were inoculated with nonsporulating mycelia and were incubated at $22^{\circ} \mathrm{C}$ under alternating light and dark conditions for $48 \mathrm{~h}$. The lesions caused by each strain are characterized by an increased accumulation of ROS in tobacco leaves. The leaves were incubated for $2 \mathrm{~h}$ in $3,3^{\prime}$-diaminobenzidine solution. Plant tissues were decolorized prior to microscopy. The bars represent $5 \mathrm{~cm}$. 
evaluate the exact mechanisms of melanin synthesis genes regulating hyphal branching in $B$. cinerea.

Fungal melanin synthesis genes have been reported to be virulence factors for several plant pathogens, such as $M$. oryzae (Howard et al. 1991) and Colletotrichum spp. (Kubo et al. 1982), because these pathogens need the accumulation of high turgor pressure in the melanized appressoria to mechanically penetrate the host plant epidermis. By contrast, $B$. cinerea, a necrotrophic pathogen, does not form melanized appressoria and invades host plants by relying on chemical weapons rather than on strong mechanical pressure (Choquer et al. 2007; van Kan 2006). In this study, deletion of bcbrnl or bcpks 13 blocked melanin biosynthesis in $B$. cinerea but enhanced its virulence, whereas overexpression of $b c b r n l$ had the opposite effect. The results are reminiscent of previous reports that showed the light-responsive transcription factor BcLTF1 and the regulatory protein BcVEL1 (VeA/VELVET) are both negatively regulating expression of melanin biosynthesis activity but their knockout mutants are both less virulent than the wild type (Schumacher et al. 2012, 2014). These studies can be partially linked to the present study, in which loss of bcbrnl and bcpks13 led to a deficiency in melanization and conidiation in vitro but enhances the virulence of $B$. cinerea. Taken together, the loss of specific melanin-biosynthesis genes can be beneficial to plant pathogenesis of $B$. cinerea.

The disease cycle of $B$. cinerea includes penetration of the host surface, killing of the host cells, and conversion of host tissue into fungal biomass (Kars and van Kan 2007). This study showed that plant cell wall constituents were more favorable for growth of the $\Delta b c b r n 1$ and $\Delta b c p k s 13$ mutants than of the wild type. Furthermore, analyses of these mutants revealed elevated activity of several secreted hydrolytic enzymes, indicating that deletion of the melanin genes could facilitate digestion of plant cell-wall compounds. In Alternaria brassicicola, loss of the transcription factor Arm1, which is important for melanin biosynthesis, results in increased expression of hydrolytic enzyme-coding genes and the virulence of this pathogen (Cho et al. 2012). In Bipolaris sorokiniana, the melanin content was negatively correlated with its secretion of extracellular enzymes and aggressiveness on the host plant (Chand et al. 2014). Additionally, nonmelanized mutants of Gaeumannomyces graminis var. graminis exhibited greater extracellular enzyme activity than the melanized wild type (Frederick et al. 1999). Thus, these data suggest that increased melanin biosynthetic activity adversely affects the secretion of chemical virulence factors in several fungi, although the mechanisms for this inhibition remain unknown.

Compared with the wild-type strain, the $\Delta b c b r n 1$ and $\Delta b c p k s 13$ mutants displayed increased virulence and rapidly induced the accumulation of more ROS in tobacco leaves, while the mutants didn't show any advantage in expression of ROS synthesis genes compared with the wild type (data not shown), indicating that infection by the mutants could also induce much stronger plant responses compared with the wild-type strain. Some signal molecules from $B$. cinerea may be toxic or recognized as elicitors to initiate defense responses in the host tissue, especially including an oxidative burst and hypersensitive cell death, which, however, could eventually facilitate the virulence of this necrotrophic pathogen (Govrin and Levine 2000; Miya et al. 2007). Even the endopolygalacturonase 1 (BcPG1) secreted by $B$. cinerea is likely also a signal that triggers suicide in plant cells, besides acting as an enzyme to degrade constituents of plant cell walls during disease development (Zhang et al. 2014). The enhanced extracellular enzymatic secretion by the $\Delta b c b r n 1$ and $\Delta b c p k s 13$ mutants could have the advantage of inducing necrotic reactions of the host tissues. In addition, shunt-pathway metabolites of melanin biosynthesis produced by the mutants are also reported to be phytotoxic to host plants (Abou-Mansour et al. 2004). Taken together, the hypervirulence of $\Delta b c b r n 1$ and $\Delta b c p k s 13$ could be due to the altered host response by the changes in fungal components or secreted elicitors.

In summary, the present study reports two melanin biosynthesis genes, bcpks13 and bcbrnl, are involved in vegetative development and conidiation that suppress fungal virulence. Interestingly, we have recently found that the mutants of another melanogenesis gene, bcscd1, were deficient in melanization but showed reduced virulence (data not shown). Thus, it can be reasonably hypothesized that melanin itself seems not to be a direct factor affecting virulence of $B$. cinerea, but the genes of the melanin-synthesis pathway or their related metabolic products may be regulating it, and this hypothesis is worth further study.

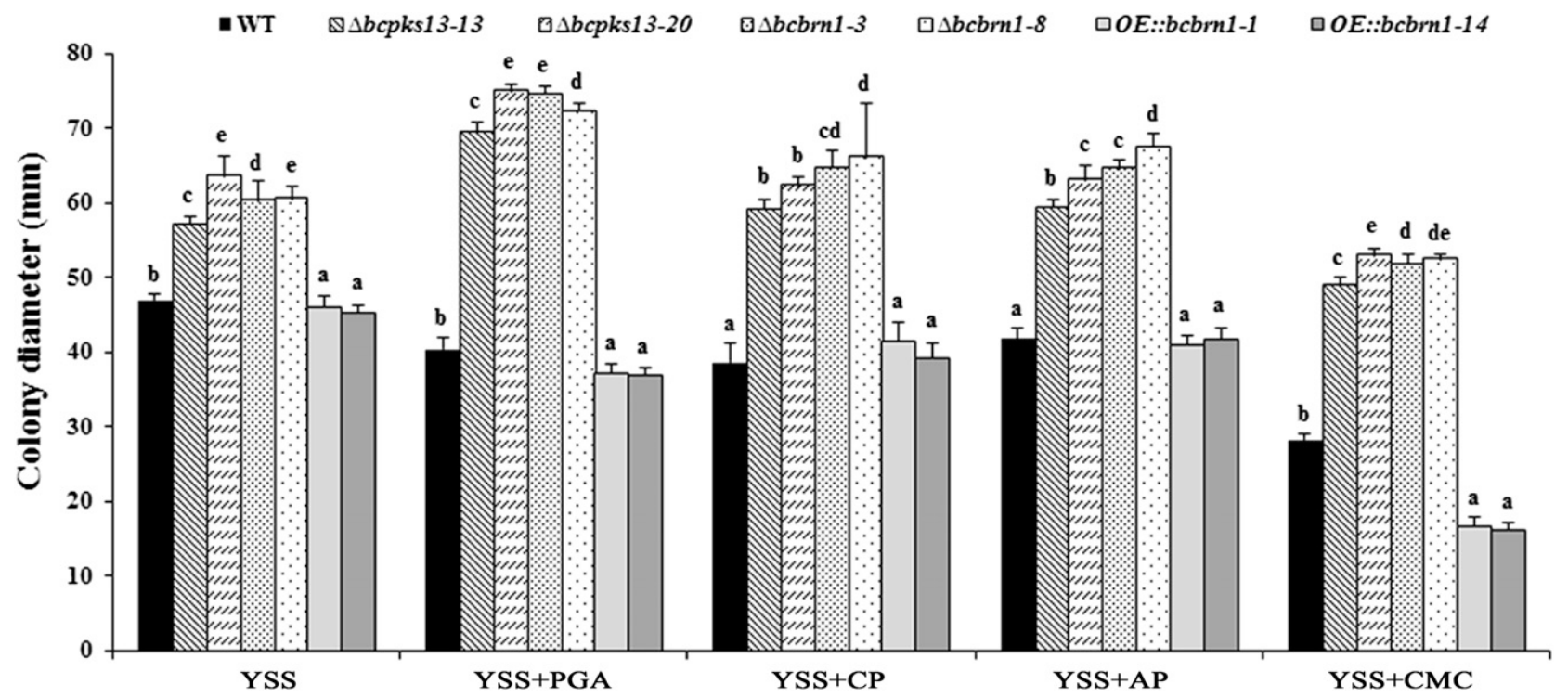

Fig. 7. Carbohydrate utilization of the $\Delta b c b r n 1$ and $\Delta b c p k s 13$ strains of Botrytis cinerea. The strains were cultured on yeast-sugar-salt (YSS) medium supplemented with polygalacturonic acid, apple pectin, citrus pectin, or carboxymethyl cellulose, respectively, in place of glucose for carbon source at $22^{\circ} \mathrm{C}$ under alternating light and dark conditions. The mean values indicated by the same letter in each row are not significantly different. $P<0.05$, analysis of variance with Duncan's multiple range tests. 


\section{MATERIALS AND METHODS}

\section{Strains and growth conditions.}

B. cinerea B05.10 (provided by R. M. Patel, University of Bristol, U.K.) was used as a recipient strain for the genereplacement experiments and as a wild-type control. Strains were cultured on YSS medium (per liter: $2 \mathrm{~g}$ of yeast extract, $10 \mathrm{~g}$ of glucose, $2 \mathrm{~g}$ of $\mathrm{KH}_{2} \mathrm{PO}_{4}, 1.5 \mathrm{~g}$ of $\mathrm{K}_{2} \mathrm{HPO}_{4}, 1 \mathrm{~g}$ of $\left(\mathrm{NH}_{4}\right)_{2} \mathrm{SO}_{4}$, and $0.5 \mathrm{~g}$ of $\left.\mathrm{MgSO}_{4} \cdot 7 \mathrm{H}_{2} \mathrm{O}\right)$ for normal vegetative growth and morphology observation, $1 \%$ water-agar medium was used for analyzing hyphal branching. The results of acidification were monitored on solid $\mathrm{CM}, \mathrm{pH} 6.5$, supplemented with bromothymol blue as a $\mathrm{pH}$ indicator, according to Canessa et al. (2013). The change in color from green to yellow indicates acidification $(\mathrm{pH}<6.0)$. The strains were cultured at $22^{\circ} \mathrm{C}$ under alternating light and dark conditions.

\section{Sequence analysis of melanin synthesis-related genes.}

The sequences of predicted melanin-synthesis genes of B05.10 were obtained from the Broad Institute Fungal Genome Initiative B. cinerea database. The related genes of BRN and
PKS in Cochliobolus heterostrophus, Magnaporthe oryzae, Colletotrichum lagenarium, Alternaria alternata, and Bipolaris oryzae were retrieved from the National Center for Biotechnology Information databases. Alignments of the amino acid sequences were performed using the Clustal $\times 1.83$ program (Chenna et al. 2003).

\section{Extraction of RNA and qRT-PCR analysis.}

For relative gene-expression studies, experiments were conducted and samples were collected as follows: $200 \mu \mathrm{l}$ of $10^{6}$ conidia/ml was inoculated on solid YSS medium with cellophane overlays and was incubated at $22^{\circ} \mathrm{C}$ under alternating light and dark conditions. Samples were collected at the indicated time points. The 8- to 12-h time points represent spore germination and appressoria formation stages, 24- to 72-h time points represent the mycelial development stages, and the 7-day time point represents the conidiation stages. Samples were also collected during sclerotia formation. Total RNA was extracted using Qiagen Reagent, and $1 \mu \mathrm{g}$ of each RNA sample was used for reverse transcription with the Prime Script RT reagent kit (Perfect Real Time) (TakaRa Biotechnology Co.). The real-time PCR
A

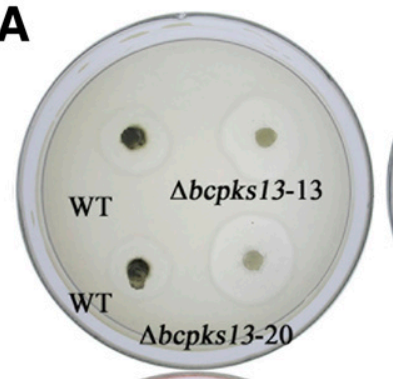

B
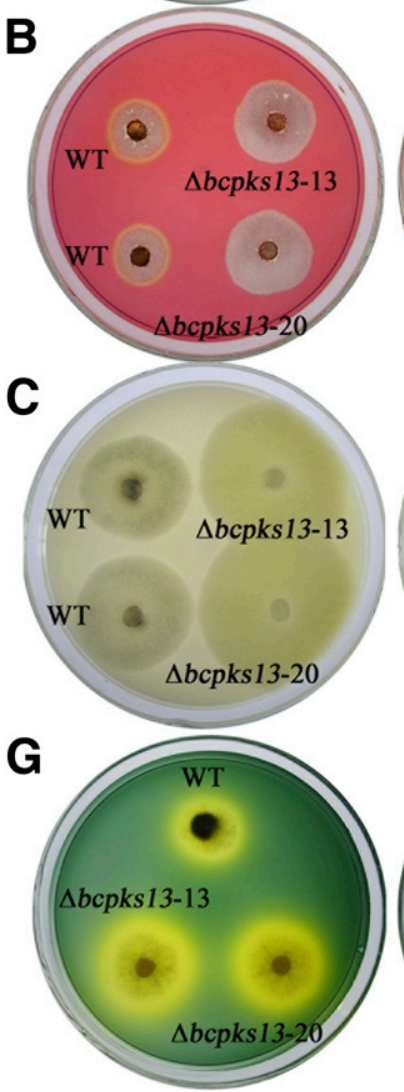
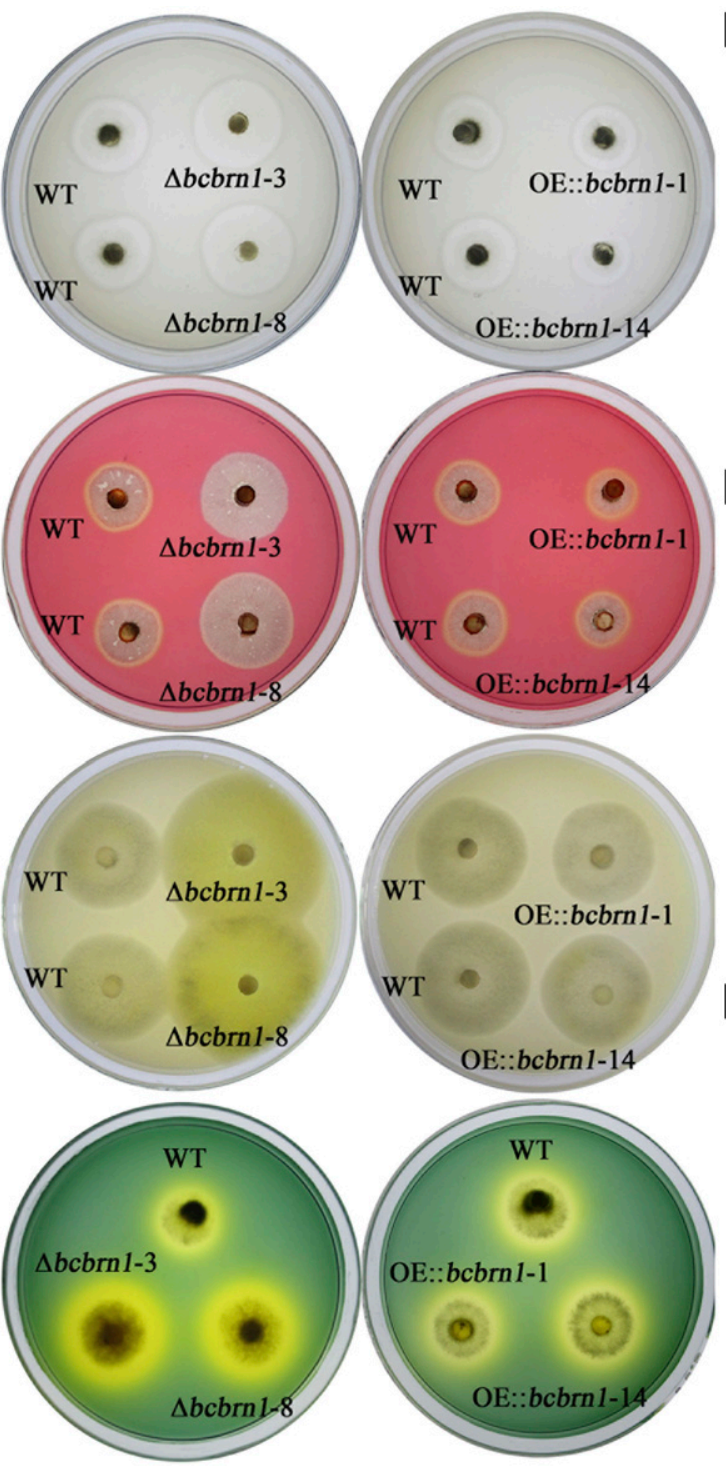

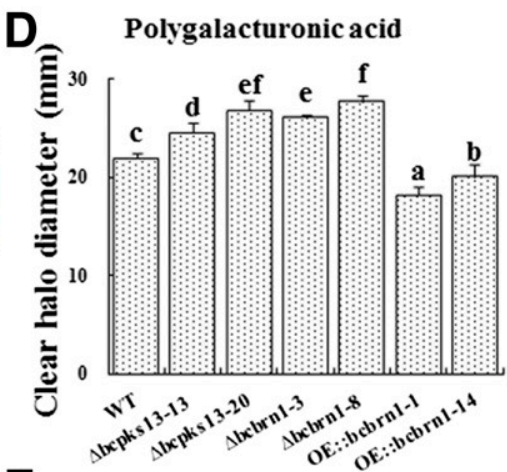

$E$

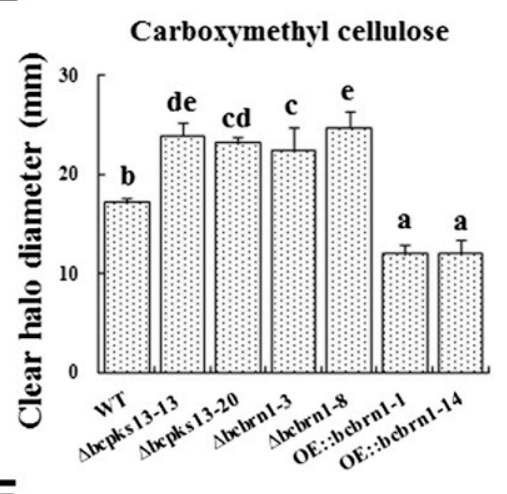

$\mathbf{F}$

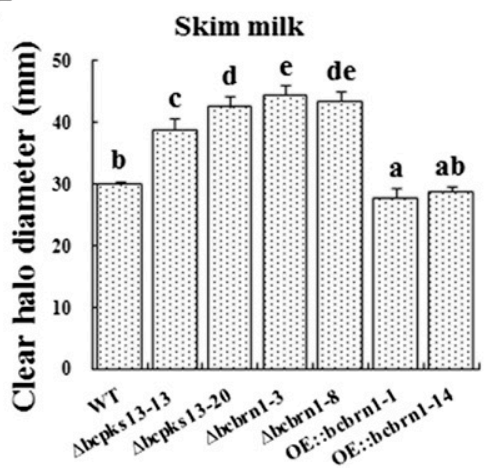

Fig. 8. Secretion of virulence factors in the $\Delta b c b r n 1, \Delta b c p k s 13$, and wild-type strains of Botrytis cinerea. Strains were incubated for 2 days on A, media specifically supplemented with polygalacturonic acid, B, carboxymethyl cellulose, or $\mathbf{C}$, skim milk at $22^{\circ} \mathrm{C}$, under alternating light and dark conditions. The secretion activities of $\mathbf{D}$, extracellular polygalacturonase, $\mathbf{E}$, cellulase, or $\mathbf{F}$, protease were measured with transparent-ring assays. G, Acidification capability was measured via the chromogenic reaction of bromothymol blue, which turned to yellow when the original alkaline $\mathrm{pH}$ in the medium was acidified to $\mathrm{pH}<6$. 
amplifications were conducted in a CFX96 real-time system (Bio-Rad, Inc.) using TakaRa SYBR Premix Ex Taq (TakaRa Biotechnology Co.). The relative quantification real-time PCR amplifications were performed with the following parameters: initial preheating at $95^{\circ} \mathrm{C}$ for $30 \mathrm{~s}$, followed by 39 cycles at $95^{\circ} \mathrm{C}$ for $5 \mathrm{~s}, 60^{\circ} \mathrm{C}$ for $30 \mathrm{~s}$. Then, melting curves were obtained based on a standard protocol $\left(65^{\circ} \mathrm{C}\right.$ to $95^{\circ} \mathrm{C}$, increment $0.5^{\circ} \mathrm{C}$ for $\left.5 \mathrm{~s}\right)$ and were used to identify the PCR product. A single melt peak was observed in all the primer sets during relative expression in the SYBR green assay. Standard quantification curves with several serial twofold dilutions of RT-qPCR products were employed to calculate the amplification efficiency (E) of each gene. The obtained E values are also shown in Supplementary Table S2. For each sample, the expression of the $\beta$-tubulin gene was used as an internal reference. There were three replicates for each sample. The experiment was repeated three times. The geneexpression levels were calculated using the $2^{-\Delta \Delta \mathrm{Ct}}$ method (Livak and Schmittgen 2001).

\section{Construction of the gene replacement cassette.}

The bcbrnl gene of the wild-type strain was deleted using the targeted replacement method of the 'split-marker recombination' strategy (Catlett et al. 2003). The deletion cassettes were constructed by fusion PCR, and the entire length (979 bp) of the target gene was replaced with a hygromycin B phosphotransferase gene $(h p h)$ cassette, obtained from the plasmid pCAMBI1300 modified with the oliC promoter from Aspergillus nidulans. First, the $5^{\prime}$ untranslated region (UTR) (1,055 bp) and 3' UTR (987 bp) fragments of bcbrnl and the two parts of the $h p h$ cassette $(1,862$ and 1,877 bp) were amplified from the wildtype genomic DNA and $h p h$ cassette templates, using primers 1 to 8 . The $5^{\prime}$ UTR and forward $h p h$ cassette were fused using primers 1 and 4, whereas the $3^{\prime}$ UTR and reverse $h p h$ cassette were fused using primers 5 and 8, producing the up- and downtransformation fragments, respectively. The resulting two major PCR fragments were gel purified and were used to transform the wild-type strain by protoplast transformation. The bcpks 13 gene of the wild-type strain was deleted using the same approach.

The overexpression vector for the bcbrnl gene was constructed with bcbrn1 cDNA. A full-length cDNA clone (870 bp) was amplified by PCR using primers 31 and 32 . $B$. cinerea bcactA promoter (Bc_08198.1, 1,500 bp) and $\beta$-glucanase terminator (BC1T_00642, 500 bp) were amplified from genomic DNA using primer sets 29 and 30, 33 and 34, respectively. The three PCR fragments were ligated by fusion PCR, using primers 29 and 34 and were cloned into the KpnI and $X b a \mathrm{I}$ restriction sites of pCAMBI1300. Then, $h p h$ was excised with $X b a \mathrm{I}$ and $\mathrm{SalI}$ restriction enzymes and was cloned into pCAMBI1300 to produce the pCAMBI1300-hph-bcbrn1 overexpression plasmid.

\section{Transformation of $\boldsymbol{B}$. cinerea and screening for the transformants.}

Protoplast preparation and transformation of $B$. cinerea were performed according to the protocol described by Patel et al. (2008). The wild-type bcbrnl gene, the up and down insert sites of the transformation fragments, and the fused $h p h$ were identified using primer pairs of 9 and 10,11 and 12,13 and 14, and 15 and 16, respectively. The bcbrn 1 disruption mutants were further verified by Southern blot hybridization, according to standard protocol. Briefly, genomic DNA extracted from $B$. cinerea was digested with the $X b a I$ restriction enzyme. The samples were subsequently resolved on a $1.4 \%$ agarose gel, were blotted onto Zeta-Probe membranes (Bio-Rad), and were probed with $\left[\alpha-{ }^{32} \mathrm{P}\right]$ dCTP radio-labeled DNA fragments of full-length $b c b r n 1$, which were amplified with primers 1 and 6 (Fig. 2A). The bcpks13 disruption mutants and overexpression strains for the bcbrnl gene were verified via similar procedures by PCR with primers 27 and 28, 19 and 26, and 29 and 34.

\section{Detection of melanin biosynthesis via the copper-sulfide-silver staining.}

A copper sulfide-silver staining method for filamentous fungi described by Butler et al. (2005) was used to detect the melanin accumulation in $B$. cinerea strains via light microscopic analysis. Briefly, copper ions bind to fungal melanin, followed by formation of the copper sulfide at melanin sites by incubation with a sodium sulfide solution. The deposited copper sulfide can be further amplified into vivid black stains using a silver enhancement step. In this study, the hyphal samples of each strain were harvested from cultures on YSS media for 7 days at $22^{\circ} \mathrm{C}$ under alternating light and dark conditions. For light microscopic observation, the samples were preincubated in $10 \mathrm{mM}$ copper chloride at room temperature for $1 \mathrm{~h}$. After that, the samples were washed six times in distilled water and were then incubated with sodium sulfide solution $(1 \%)$ in the dark for another $1 \mathrm{~h}$. The samples were subsequently washed six times before the last step of silver staining. The samples processed through the staining procedures were dropped into $50 \mu \mathrm{l}$ of water on a slide, and a cover slip was applied. The slides were viewed through a Motic microscope AE2000T and were photographed using a Pro252A digital microscope camera.

\section{Phenotypic analysis.}

To compare the colony morphology of the wild type, mutants, and overexpression strains, radial growth was measured daily, following central inoculation of mycelial plugs $(5 \mathrm{~mm})$ excised from the edge of 3 -day-old colonies at $22^{\circ} \mathrm{C}$ in the dark. Each strain was tested with three parallel samples, and the experiment was conducted independently three times. After being cultured for 14 days at $22^{\circ} \mathrm{C}$ under alternating light and dark conditions, conidia production was examined by light microscopy. To visualize hyphae branching in vitro, young mycelium plugs were inoculated onto cellophane sheets that were overlaid on water agar $(1 \%)$ and samples were analyzed by light microscopy. To visualize hyphae development on the host, mycelium plugs were inoculated onto onion epidermal layers, which were overlaid on water agar $(1 \%)$ and were incubated in moist conditions at $22^{\circ} \mathrm{C}$. Mycelia on the surface of the onion epidermis were stained with trypan blue according to Koch and Slusarenko (1990). The cultures were inspected microscopically.

\section{Virulence assay.}

Mycelium plugs of $5 \mathrm{~mm}$ in diameter were excised from the actively growing edge of the colonies and were then inoculated onto the surface of pepper (eight biological replicates) and apple slices (10 biological replicates). The surfaces of the pepper fruits were wounded with a needle prior to inoculation. The infected fruits were incubated in a container with high humidity at $22^{\circ} \mathrm{C}$ under alternating light and dark conditions. The lesion diameters were measured after 2 (apple) or 3 (pepper) days of inoculation. All the experiments were performed three times, and the data obtained in these experiments were analyzed with analysis of variance (ANOVA), followed by Duncan's multiple range tests $(P<0.05)$ for means comparison with the use of SPSS 17.0. The mycelium plugs were inoculated onto the leaves of tobacco without prior wounding. The infected leaves were incubated in plastic boxes at $22^{\circ} \mathrm{C}$ under alternating light and dark conditions. Disease symptoms were scored after 2 days of incubation.

To visualize the accumulation of ROS in the infected tobacco leaves, DAB (Sigma-Aldrich) staining of the lesions was performed 
as described previously (Schumacher et al. 2012), with some modification. Tobacco leaves taken at 20 and $48 \mathrm{hpi}$ were first incubated at room temperature for $2 \mathrm{~h}$ in $0.1 \% \mathrm{DAB}$ solution (10 mM Na $2 \mathrm{HPO}_{4} \mathrm{DAB}$ staining solution, $\mathrm{pH}$ 3.0). Following incubation, the DAB staining solution was replaced with a bleaching solution (96\% ethanol). Then, the chlorophyll was extracted by incubating the leaves for $5 \mathrm{~min}$ in boiling ethanol. After that, the bleaching solution was replaced with fresh bleaching solution. The sample areas with ROS accumulation were subsequently visualized as a brown color caused by DAB staining.

\section{Assays for utilization of host polymers.}

Mycelial growth tests in the presence of different host polymers were performed on YSS media supplemented with PGA, apple pectin, citrus pectin, or carboxymethyl cellulose as carbon sources at $22^{\circ} \mathrm{C}$ under alternating light and dark conditions for 3 days. Each plate was inoculated with a mycelial plug on YSS media as described above. The radial growth rate of each strain was measured by determining colony diameters.

\section{Hydrolytic enzyme secretion activity assays.}

Plate assays for polygalacturonase, cellulase, and protease secretion activities were performed by measuring the transparent halo surrounding the fungal colonies after either precipitation or staining of the substrates PGA (Sigma, Madrid), CMC, or skimmed milk powder (Wondersun), respectively. A 5 -mm diameter mycelium plug was inoculated on each specific plate and was cultured at $22^{\circ} \mathrm{C}$ under alternating light and dark conditions. The polygalacturonase activity was analyzed by precipitating the PGA plates with $0.4 \mathrm{M} \mathrm{HCl}$ for $5 \mathrm{~min}$, according to Scott-Craig et al. (1990). The cellulase activity was analyzed according to Rispail and Di Pietro (2009). The CMC plates were stained for 30 min with $0.1 \%$ Congo red (Sigma), followed by 30 min of destaining with $0.1 \mathrm{M} \mathrm{NaCl}$. The protease activity was analyzed according to Gronover et al. (2001), with some modification. Each strain was cultured on casein agar (2.5\% skim milk, $2 \mathrm{~g}$ per liter of $\mathrm{K}_{2} \mathrm{HPO}_{4}$, and $16 \mathrm{~g}$ of agar, $\mathrm{pH} 6.5$ ) at $22^{\circ} \mathrm{C}$, under alternating light and dark conditions. The secretion of proteases resulted in the formation of transparent halos around the colonies.

\section{Statistical analysis.}

The data obtained in this study were analyzed with ANOVA followed by Duncan's multiple range tests $(P<0.05)$ for means comparison, with the use of SPSS 17.0.

\section{ACKNOWLEDGMENTS}

We thank M. Hahn (University of Kaiserslautern, Germany) for critical comments to improve this article. This work was carried out with the support of National Natural Science Foundation of China (31172008), the National High Technology Research and Development Program of China (863, 2012AA101607), and a grant from Science and Technology Commission of Shanghai Municipality (15YF1403300).

\section{LITERATURE CITED}

Abou-Mansour, E., Couche, E., and Tabacchi, R. 2004. Do fungal naphthalenones have a role in the development of esca symptoms? Phytopathol. Mediterr. 43:75-82.

Akamatsu, H. O., Chilvers, M. I., Stewart, J. E., and Peever, T. L. 2010. Identification and function of a polyketide synthase gene responsible for 1,8-dihydroxynaphthalene-melanin pigment biosynthesis in Ascochyta rabiei. Curr. Genet. 56:349-360.

Amselem, J., Cuomo, C. A., van Kan, J. A., Viaud, M., Benito, E. P., Couloux, A., Coutinho, P. M., de Vries, R. P., Dyer, P. S., Fillinger, S., Fournier, E., Gout, L., Hahn, M., Kohn, L., Lapalu, N., Plummer, K. M., Pradier, J. M., Quévillon, E., Sharon, A., Simon, A., ten Have, A., Tudzynski, B., Tudzynski, P., Wincker, P., Andrew, M., Anthouard, V., Beever, R. E., Beffa, R., Benoit, I., Bouzid, O., Brault, B., Chen, Z.,
Choquer, M., Collémare, J., Cotton, P., Danchin, E. G., Da Silva, C., Gautier, A., Giraud, C., Giraud, T., Gonzalez, C., Grossetete, S., Güldener, U., Henrissat, B., Howlett, B. J., Kodira, C., Kretschmer, M., Lappartient, A., Leroch, M., Levis, C., Mauceli, E., Neuvéglise, C., Oeser, B., Pearson, M., Poulain, J., Poussereau, N., Quesneville, H. Rascle, C., Schumacher, J., Ségurens, B., Sexton, A., Silva, E., Sirven, C., Soanes, D. M., Talbot, N. J., Templeton, M., Yandava, C., Yarden, O., Zeng, Q., Rollins, J. A., Lebrun, M. H., and Dickman, M. 2011. Genomic analysis of the necrotrophic fungal pathogens Sclerotinia sclerotiorum and Botrytis cinerea. PLoS Genet. 7:e1002230.

Bell, A. A., and Wheeler, M. H. 1986. Biosynthesis and functions of fungal melanins. Annu. Rev. Phytopathol. 24:411-451.

Butler, M. J., and Day, A. W. 1998. Fungal melanins: A review. Can. J. Microbiol. 44:1115-1136.

Butler, M. J., Gardiner, R. B., and Day, A. W. 2005. Fungal melanin detection by the use of copper sulfide-silver. Mycologia 97:312-319.

Canessa, P., Schumacher, J., Hevia, M. A., Tudzynski, P., and Larrondo, L. F. 2013. Assessing the effects of light on differentiation and virulence of the plant pathogen Botrytis cinerea: Characterization of the White Collar complex. PLoS ONE 8:e84223.

Catlett, N. L., Lee, B. N., Yoder, O. C., and Turgeon, B. G. 2003. Split-marker recombination for efficient targeted deletion of fungal genes. Fungal Genet. Newsl. 50:9-11.

Chand, R., Kumar, M., Kushwaha, C., Shah, K., and Joshi, A. K. 2014. Role of melanin in release of extracellular enzymes and selection of aggressive isolates of Bipolaris sorokiniana in barley. Curr. Microbiol. 69:202-211.

Chenna, R., Sugawara, H., Koike, T., Lopez, R., Gibson, T. J., Higgins, D. G., and Thompson, J. D. 2003. Multiple sequence alignment with the Clustal series of programs. Nucleic Acids Res. 31:3497-3500.

Cho, Y., Srivastava, A., Ohm, R. A., Lawrence, C. B., Wang, K. H. Grigoriev, I. V., and Marahatta, S. P. 2012. Transcription factor Amr1 induces melanin biosynthesis and suppresses virulence in Alternaria brassicicola. PLoS Pathog. 8:e1002974.

Choquer, M., Fournier, E., Kunz, C., Levis, C., Pradier, J. M., Simon, A., and Viaud, M. 2007. Botrytis cinerea virulence factors: New insights into a necrotrophic and polyphageous pathogen. FEMS (Fed. Eur. Microbiol. Soc.) Microbiol. Lett. 277:1-10.

Dean, R., Van Kan, J. A., Pretorius, Z. A., Hammond-Kosack, K. E., Di Pietro, A., Spanu, P. D., Rudd, J. J., Dickman, M., Kahmann, R., Ellis, J., and Foster, G. D. 2012. The top 10 fungal pathogens in molecular plant pathology. Mol. Plant Pathol. 13:414-430.

Doss, R. P., Deisenhofer, J., Krug von Nidda, H.-A., Soeldner, A. H., and McGuire, R. P. 2003. Melanin in the extracellular matrix of germlings of Botrytis cinerea. Phytochemistry 63:687-691.

Eisenman, H. C., and Casadevall, A. 2012. Synthesis and assembly of fungal melanin. Appl. Microbiol. Biotechnol. 93:931-940.

El Oirdi, M., El Rahman, T. A., Rigano, L., El Hadrami, A., Rodriguez, M. C., Daayf, F., Vojnov, A., and Bouarab, K. 2011. Botrytis cinerea manipulates the antagonistic effects between immune pathways to promote disease development in tomato. Plant Cell 23:2405-2421.

Eliahu, N., Igbaria, A., Rose, M. S., Horwitz, B. A., and Lev, S. 2007. Melanin biosynthesis in the maize pathogen Cochliobolus heterostrophus depends on two mitogen-activated protein kinases, Chk1 and Mps1, and the transcription factor Cmr1. Eukaryot. Cell 6:421-429.

Frederick, B. A., Caesar-Ton That, T. C., Wheeler, M., Sheehan, K. B., Edens, W. A., and Henson, J. M. 1999. Isolation and characterization of Gaeumannomyces graminis var. graminis melanin mutants. Mycol. Res. 103:99-110.

Gourgues, M., Brunet-Simon, A., Lebrun, M. H., and Levis, C. 2004. The tetraspanin BcPls1 is required for appressorium-mediated penetration of Botrytis cinerea into host plant leaves. Mol. Microbiol. 51:619-629.

Govrin, E. M., and Levine, A. 2000. The hypersensitive response facilitates plant infection by the necrotrophic pathogen Botrytis cinerea. Curr. Biol. 10:751-757.

Gronover, C. S., Kasulke, D., Tudzynski, P., and Tudzynski, B. 2001. The role of $\mathrm{G}$ protein $\alpha$ subunits in the infection process of the gray mold fungus Botrytis cinerea. Mol. Plant-Microbe Interact. 14:1293-1302.

Harris, S. D. 2008. Branching of fungal hyphae: Regulation, mechanisms and comparison with other branching systems. Mycologia 100:823-832.

Heller, J., and Tudzynski, P. 2011. Reactive oxygen species in phytopathogenic fungi: Signaling, development, and disease. Annu. Rev. Phytopathol. 49:369-390.

Hill, H. Z. 1992. The function of melanin or six blind people examine an elephant. BioEssays 14:49-56.

Howard, R. J., Ferrari, M. A., Roach, D. H., and Money, N. P. 1991. Penetration of hard substrates by a fungus employing enormous turgor pressures. Proc. Natl. Acad. Sci. U.S.A. 88:11281-11284. 
Jarvis, W. R. 1977. Botryotinia and Botrytis species: Taxonomy, physiology and pathogenicity. A guide to the literature, Monograph no. 14, Research Branch, Canada Department of Agriculture, Ottawa, Canada.

Kars, I., and van Kan, J. A. 2007. Extracellular enzymes and metabolites involved in pathogenesis of Botrytis. Pages 99-118 in: Botrytis: Biology, Pathology and Control. Y. Elad, B. Williamson, P. Tudzynski, and N. Delen, eds. Kluwer Academic Publishers, Dordrecht, The Netherlands.

Kawamura, C., Tsujimoto, T., and Tsuge, T. 1999. Targeted disruption of a melanin biosynthesis gene affects conidial development and UV tolerance in the Japanese pear pathotype of Alternaria alternata. Mol. Plant-Microbe Interact. 12:59-63.

Kheder, A. A., Akagi, Y., Akamatsu, H., Yanaga, K., Maekawa, N., Otani, H., Tsuge, T., and Kodama, M. 2012. Functional analysis of the melanin biosynthesis genes $A L M 1$ and BRM2-1 in the tomato pathotype of Alternaria alternate. J. Gen. Plant Pathol. 78:30-38.

Kihara, J., Moriwaki, A., Ito, M., Arase, S., and Honda, Y. 2004. Expression of THR1, a 1,3,8-trihydroxynaphthalene reductase gene involved in melanin biosynthesis in the phytopathogenic fungus Bipolaris oryzae, is enhanced by near-ultraviolet radiation. Pigment Cell Res. 17:15-23.

Koch, E., and Slusarenko, A. 1990. Arabidopsis is susceptible to infection by a downy mildew fungus. Plant Cell 2:437-445.

Kubo, Y., and Furusawa, I. 1991. Melanin biosynthesis: Prerequisite for successful invasion of the plant host by appressoria of Colletotrichum and Pyricularia. Pages 205-218 in: The Fungal Spore and Disease Initiation in Plants and Animals. G. T. Cole and H. C. Hoch, eds. Plenum Publishing, New York.

Kubo, Y., Nakamura, H., Kobayashi, K., Okuno, T., and Furusawa, I. 1991. Cloning of a melanin biosynthetic gene essential for appressorial penetration of Colletotrichum lagenarium. Mol. Plant-Microbe Interact. 5:440-445.

Kubo, Y., Suzuki, K., Furusawa, I., Ishida, N., and Yamamoto, M. 1982. Relation of appressorium pigmentation and penetration of nitrocellulose membranes by Colletotrichum lagenarium. Phytopathology 72:498-501.

Leroch, M., Kleber, A., Silva, E., Coenen, T., Koppenhöfer, D., Shmaryahu, A., Valenzuela, P. D., and Hahn, M. 2013. Transcriptome profiling of Botrytis cinerea conidial germination reveals upregulation of infectionrelated genes during the prepenetration stage. Eukaryot. Cell 12: 614-626.

Liu, G. Y., and Nizet, V. 2009. Color me bad: microbial pigments as virulence factors. Trends Microbiol. 17:406-413.

Liu, W., Soulié, M. C., Perrino, C., and Fillinger, S. 2011. The osmosensing signal transduction pathway from Botrytis cinerea regulates cell wall integrity and MAP kinase pathways control melanin biosynthesis with influence of light. Fungal Genet. Biol. 48:377-387.

Livak, K. J., and Schmittgen, T. D. 2001. Analysis of relative gene expression data using real-time quantitative PCR and the $2^{-\Delta \Delta \mathrm{Ct}}$ method. Methods 25:402-408

Ludwig, N., Löhrer, M., Hempel, M., Mathea, C, Schliebner, I., Menzel, M., Kiesow, A., Schaffrath, U., Deising, H. B., and Horbach, R. 2014. Melanin is not required for turgor generation but enhances cell-wall rigidity in appressoria of the corn pathogen Colletotrichum graminicola. Mol. Plant-Microbe Interact. 27:315-327.

Miya, A., Albert, P., Shinya, T., Desaki, Y., Ichimura, K., Shirasu, K., Narusaka, Y., Kawakami, N., Kaku, H., and Shibuya, N. 2007. CERK1, a LysM receptor kinase, is essential for chitin elicitor signaling in Arabidopsis. Proc. Natl. Acad. Sci. U.S.A. 104:19613-19618.

Moriwaki, A., Kihara, J., Kobayashi, T., Tokunaga, T., Arase, S., and Honda, Y. 2004. Insertional mutagenesis and characterization of a polyketide synthase gene (PKS1) required for melanin biosynthesis in Bipolaris oryzae. FEMS (Fed. Eur. Microbiol. Soc.) Microbiol. Lett. 238:1-8.

Patel, R. M., Heneghan, M. N., van Kan, J. A., Bailey, A. M., and Foster, G. D. 2008. The pOT and pLOB vector systems: improving ease of transgene expression in Botrytis cinerea. J. Gen. Appl. Microbiol. 54:367-376.

Perpetua, N. S., Kubo, Y., Yasuda, N., Takano, Y., and Furusawa, I. 1996. Cloning and characterization of a melanin biosynthetic THR1 reductase gene essential for appressorial penetration of Colletotrichum lagenarium. Mol. Plant-Microbe Interact. 9:323-329.

Rispail, N., and Di Pietro, A. 2009. Fusarium oxysporum Ste12 controls invasive growth and virulence downstream of the Fmk1 MAPK cascade. Mol. Plant-Microbe Interact. 22:830-839.
Schumacher, J., Pradier, J. M., Simon, A., Traeger, S., Moraga, J., Collado, I. G., Viaud, M., and Tudzynski, B. 2012. Natural variation in the VELVET gene bcvell affects virulence and light-dependent differentiation in Botrytis cinerea. PLoS ONE 7:e47840.

Schumacher, J., Simon, A., Cohrs, K. C., Viaud, M., and Tudzynski, P. 2014. The transcription factor BcLTF1 regulates virulence and light responses in the necrotrophic plant pathogen Botrytis cinerea. PLoS Genet. 10:e1004040.

Scott-Craig, J. S., Panaccione, D. G., Cervone, F., and Walton, J. D. 1990. Endopolygalacturonase is not required for pathogenicity of Cochliobolus carbonum on maize. Plant Cell 2:1191-1200.

Singh, S., Malhotra, A. G., Pandey, A., Pandey, K. M. 2013. Computational model for pathway reconstruction to unravel the evolutionary significance of melanin synthesis. Bioinformation. 9:94-100.

Tenberge, K. B. 2004. Morphology and cellular organisation in Botrytis interactions with plants. Pages 67-84 in: Botrytis: Biology, Pathology and Control. Y. Elad, B. Williamson, P. Tudzynski, and N. Delen, eds. Kluwer Academic Publishers, Dordrecht, The Netherlands.

Thompson, J. E., Fahnestock, S., Farrall, L., Liao, D. I., Valent, B., and Jordan, D. B. 2000. The second naphthol reductase of fungal melanin biosynthesis in Magnaporthe grisea tetrahydroxynaphthalene reductase. J. Biol. Chem. 275:34867-34872.

Tsai, H.-F., Fujii, I., Watanabe, A., Wheeler, M. H., Chang, Y. C., Yasuoka, Y., Ebizuka, Y., and Kwon-Chung, K. J. 2001. Pentaketide melanin biosynthesis in Aspergillus fumigatus requires chain-length shortening of a heptaketide precursor. J. Biol. Chem. 276:29292-29298.

Tsuji, G., Kenmochi, Y., Takano, Y., Sweigard, J., Farrall, L., Furusawa, I., Horino, O., and Kubo, Y. 2000. Novel fungal transcriptional activators, Cmr1p of Colletotrichum lagenarium and pig1p of Magnaporthe grisea, contain Cys2His2 zinc finger and Zn(II)2Cys6 binuclear cluster DNAbinding motifs and regulate transcription of melanin biosynthesis genes in a developmentally specific manner. Mol. Microbiol. 38:940-954.

van Kan, J. A. 2006. Licensed to kill: The lifestyle of a necrotrophic plant pathogen. Trends Plant Sci. 11:247-253.

Wang, H.-L., Kim, S. H., and Breuil, C. 2001. A scytalone dehydratase gene from Ophiostoma floccosum restores the melanization and pathogenicity phenotypes of a melanin-deficient Colletotrichum lagenarium mutant. Mol. Genet. Genomics 266:126-132.

Weiberg, A., Wang, M., Lin, F. M., Zhao, H., Zhang, Z., Kaloshian, I., Huang, H. D., and Jin, H. 2013. Fungal small RNAs suppress plant immunity by hijacking host RNA interference pathways. Science 342: 118-123.

Wheeler, M. H., Tolmsoff, W. J., Bell, A. A., and Mollenhauer, H. H. 1978. Ultrastructural and chemical distinction of melanins formed by Verticillium dahliae from (+)-scytalone, 1,8-dihydroxynaphthalene, catechol, and L-3,4-dihydroxyphenylalanine. Can. J. Microbiol. 24: 289-297.

Yang, Q., Chen, Y., and Ma, Z. 2013a. Involvement of BcVeA and BcVelB in regulating conidiation, pigmentation and virulence in Botrytis cinerea. Fungal Genet. Biol. 50:63-71.

Yang, Q., Yu, F., Yin, Y., and Ma, Z. 2013b. Involvement of protein tyrosine phosphatases BcPtpA and BcPtpB in regulation of vegetative development, virulence and multi-stress tolerance in Botrytis cinerea. PLoS ONE 8:e61307.

Zeun, R., and Buchenauer, H. 1985. Einfluss von tricyclazol auf die entwicklung und melaningehalte der sklerotien von Botrytis cinerea. Phytopathol. Z. 112:259-267.

Zhang, L., Kars, I., Essenstam, B., Liebrand, T. W., Wagemakers, L., Elberse, J., Tagkalaki, P., Tjoitang, D., van den Ackerveken, G., and van Kan, J. A. 2014. Fungal endopolygalacturonases are recognized as microbeassociated molecular patterns by the Arabidopsis receptor-like protein RESPONSIVENESS TO BOTRYTIS POLYGALACTURONASES1. Plant Physiol. 164:352-364.

\section{AUTHOR-RECOMMENDED INTERNET RESOURCES}

Broad Institute Fungal Genome Initiative Botrytis cinerea database: http://www.broadinstitute.org/annotation/genome/botrytis_cinerea National Center for Biotechnology Information databases: http://www.ncbi.nlm.nih.gov 